\title{
Case report. Endo-ureterale ballonkatheter bij urinelekkage en ureterstricturen na urinedeviatie volgens Bricker
}

\author{
J. R. Oddens ${ }^{1}$ (I) - E. S. S. van den Aker ${ }^{1}$ P. L. M. Vijverberg ${ }^{2}$ H. H. E. van Melick ${ }^{2}$ T. T. C. Overtoom ${ }^{3}$
}

Published online: 7 June 2017

(C) The Author(s) 2017. This article is an open access publication.

Samenvatting Bij de aanleg van een urinedeviatie volgens Bricker komt zowel lekkage als stenosering van de anastomose voor als complicatie in de postoperatieve fase. In deze casus komen beide problemen aan bod en wordt een endoureterale oplossing beschreven waarbij een nieuw soort JJkatheter met geïntegreerde ballon wordt gebruikt.

Trefwoorden urinedeviatie - Bricker - urinelekkage stenosering $\cdot \mathrm{JJ}$-stent

\section{Case report. Endo-ureteral balooncatheter in case of urine leakage and stenosis according to Bricker}

\begin{abstract}
After creating a urinary diversion according to Bricker, leakage and stenosis of the ileo-ureteral anastomosis are recognized as postoperative complications. In the presented case description both complications are discussed, together with a possible solution using a recently developed double-J stent with an integrated balloon.
\end{abstract}

Keywords urinary diversion - Bricker · urine leakage . ureteral stenosis $\cdot \mathrm{JJ}$-stent

dr. J. R. Oddens

j.oddens@jbz.nl

1 afdeling Urologie, Jeroen Bosch Ziekenhuis, 's-Hertogenbosch, Nederland

2 afdeling Urologie, St. Antonius ziekenhuis, Nieuwegein, Nederland

3 afdeling Radiologie, Jeroen Bosch Ziekenhuis/St. Antonius ziekenhuis, 's-Hertogenbosch/Nieuwegein, Nederland

\section{Introductie}

Patiënten met een urinedeviatie volgens Bricker kunnen te maken krijgen met stricturen op de overgang van de ureter naar de lis. Dergelijke stricturen worden beschreven bij 10-14\% van de patiënten [1]. Postoperatief kan ook lekkage van de anastomose optreden. Deze situatie kan worden geaccepteerd indien de afvloedbelemmering of geringe lekkage geen klachten oplevert en ook de nierfunctie niet bedreigt, maar bij pijn, infectie of ernstig nierfunctieverlies wordt de nier meestal initieel met een nefrostomiekatheter gedraineerd. Aansluitend zal een keuze worden gemaakt: de nefrostomiekatheter handhaven, de anastomose vernieuwen, de nier wegnemen of een endoluminale oplossing zoeken voor de stenose of lekkage. Het plaatsen van een stent, antegraad of retrograad, kan de endoluminale weg openhouden of de lekkage doen stoppen, maar follow-upgegevens zijn tot op heden beperkt beschreven [2,3]. De kans dat het tijdelijk plaatsen van een JJ-stent op langere termijn voor voldoende doorgankelijkheid zorgt, lijkt beperkt. Een ballondilatatie met Acucise ${ }^{\circledR}$, met als doel blijvende dilatatie te bewerkstelligen, leidde in $30 \%$ van de gevallen tot succes [4]. Een reoperatie voor het vervangen van de anastomose is een grote interventie, waarbij soms ook de Bricker-lis moet worden vervangen, en is daarmee de meest ingrijpende oplossing.

Radioloog Overtoom ontwikkelde enkele jaren geleden een JJ-katheter met daaromheen een ballon (fig. 1). Deze werd in eerste instantie gebruikt om, na dilatatie van een uretero-pelviene stenose, de ureter met een wijdere doorgang te laten herstellen [5]. In de schacht bevinden zich drie kanalen: een wijd kanaal voor de voerdraad en de urineafvloed en twee zeer kleine kanalen: een inflatiekanaal naar de 'one-way valve' in de ballon, die via de zijpoort van de pusher gevuld wordt met contrastmiddel. Het tweede kleine 


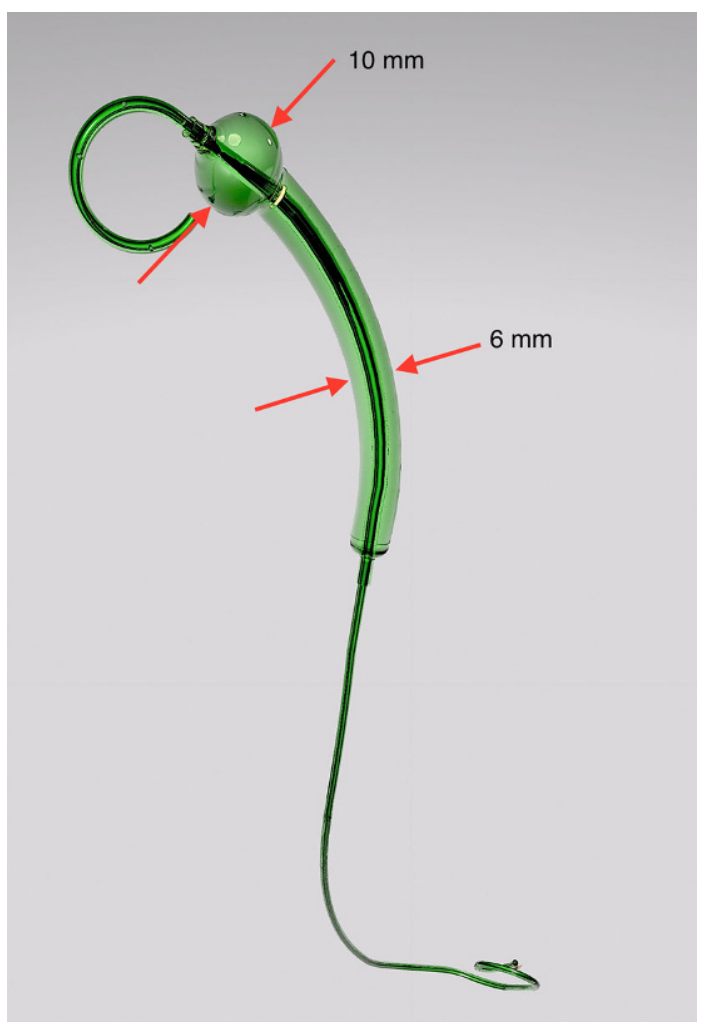

Figuur 1 Casus 1. Overzicht van de Overtoom-ballonkatheter.

kanaal staat in open verbinding met de ballon en is aan de distale kant van de katheter dicht. De ballon wordt geleegd door het distale einde af te knippen.

Wij beschrijven drie patiënten bij wie anastomoseproblemen bij een urinestoma volgens Bricker konden worden behandeld met behulp van deze Overtoom-ballon-dubbelJ-katheter (Overtoom Ltd.). Deze ballon werd gebruikt als kidney blocker (casus 1 en 2) en als spacer balloon (casus 3).

\section{Casus 1}

Een 69-jarige vrouw onderging 15 jaar geleden een cystectomie met aanleg van een urinestoma voor een goedaardige indicatie. De Bricker-lis raakte door onduidelijke oorzaak geoblitereerd, wat resulteerde in periodieke dilatatie van de nieren met aanvalsgewijze pijnklachten. Ze onderging een Bricker-lisvervanging met een nieuw stuk ileum, dat werd aangesloten op de eerder aangelegde ureteranastomose (Wallace-techniek). Haar nieuwe lis bleek te lekken op de ureteranastomose, wat werd gesignaleerd toen de achtste dag postoperatief de single J's die peroperatief waren geplaatst, werden verwijderd. Na plaatsing van een abdominale drain produceerde het stoma geen urine meer. Op dat moment waren de nieren niet gestuwd. In overleg met de interventieradioloog (TO) werd een poging gedaan om de afvloed van de nieren te blokkeren en zo de lekkage op te heffen. De procedure vond plaats op de radiologische angiokamer, zonder narcose. We plaatsten een Ch24blaaskatheter door het urostoma, bliezen de ballon op in de lis en trokken deze tegen de binnenkant van de buikwand aan om de lis tijdens de procedure af te sluiten. Via een Y-connector op de blaaskatheter werd contrastmiddel ingespoten om de lis zich te laten ontplooien, waarna de lekkage naar de buikholte zichtbaar werd. Met behulp van een korte angiografiekatheter door de blaaskatheter heen, kon rechts en links een voerdraad in de ureter worden opgevoerd. $\mathrm{Na}$ beiderzijds een Overtoom-ballonkatheter (Overtoom Ltd.) te hebben opgeblazen met contrastmiddel werd het lek met de ballon overbrugd (fig. 1). De urineproductie door de buikdrain was de volgende dag aanzienlijk afgenomen. De dagen hierna blokkeerde de schacht van beide Overtoomballonkatheters, ontstond beiderzijds hydronefrose en werden de nieren gedraineerd met nefrostomiekatheters. De abdominale drain viel droog en werd verwijderd. Twaalf dagen na plaatsing van de ballonnen werden de ballonkatheters vervangen door single-J-katheters en na 30 dagen werden de nefrostomiekatheters afgesloten en daags daarna verwijderd. Weer zes weken later werden ook de single-Jkatheters verwijderd. Bij terugkomst op de polikliniek na 15 maanden had patiënte geen klachten, bleek het serumkreatinine normaal, was er geen stuwing van de nieren en functioneerde de Bricker-lis goed.

\section{Casus 2}

Een mannelijke patiënt van 66 jaar onderging een radicale cystoprostatectomie in verband met een spierinvasief blaascarcinoom. Er werd een urinedeviatie volgens Bricker aangelegd met separaat ingehechte ureteren (links end-to-end, rechts end-to-side). Na het verwijderen van de single-Jstents ontstond koorts en een creatininestijging. Op een CT-scan werden vochtcollecties verdacht voor urinoom aan de kant van de end-to-end anastomose van de linkerureter gezien. In overleg met de interventieradioloog (TO) werd geprobeerd retrograad de lekkage te overbruggen. Hierbij lukte het niet om een voerdraad langs het urinoom te plaatsen tot in het linkernierbekken, maar kwamen we uit in het urinoom en tussen darmlissen. De rechterureter kon wel retrograad worden bereikt. Vervolgens werd een punctie gedaan van het niet-gedilateerde kelkbekkensysteem links om antegraad de lis te bereiken. Uiteindelijk lukte het met een sidewinder katheter het urostoma met de voerdraad te bereiken. Om lekkage naar de buikholte tegen te gaan, werd beiderzijds een Overtoom-ballonkatheter geplaatst, proximaal van het lek, terwijl via het aangeprikte linkersysteem een nefrostomiekatheter werd achtergelaten, om verdere lekkage en vulling van de urinomen te voor- 


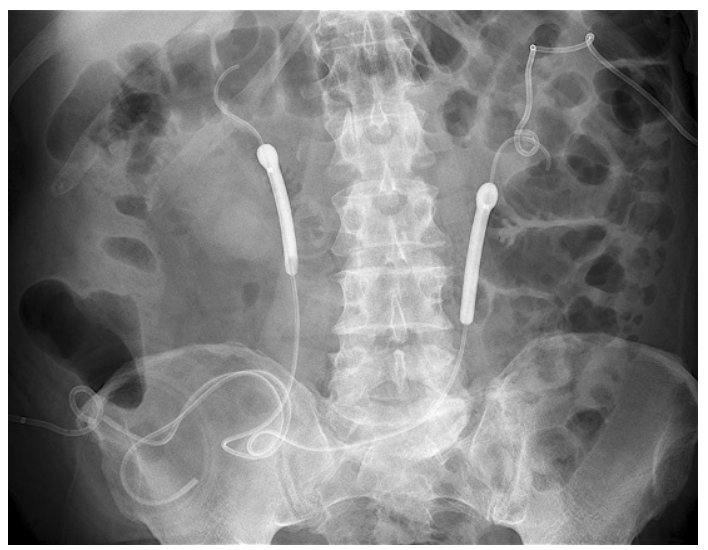

Figuur 2 Casus 2. Over beide voerdraden zijn Overtoom-ballonkatheters geplaatst ter overbrugging van de overgang van de Bricker-lis naar de ureter.

komen. Het distale deel van de Overtoom-ballonkatheter kwam in de Bricker-lis uit, waarmee de weg naar de lis gezekerd bleef (fig. 2). Na enige tijd werd de ballon rechts uitgedreven naar de urinezak van het stoma. Aan de linkerkant voorkwam de nefrostomie mogelijk de migratie van de ballon. Opspuiten van de lis, enkele dagen later, liet geen vulling zien van de urinomen. De ballon aan de linkerkant werd na twee maanden vervangen door twee single-Jkatheters aan de linkerzijde, om de afvloed te waarborgen, waarna de nefrostomiekatheter links werd verwijderd. Vanwege ziekteprogressie werd afgezien van verdere pogingen deze katheters te verwijderen.

\section{Casus 3}

De laatste patiënt is een 64-jarige man die een re-re-recidiefstrictuur kreeg van zijn ureter-Bricker-anastomose. De eerst keer werd de strictuur gedilateerd met een $6 \times 20 \mathrm{~mm}$ cutting balloon (Boston Scientific Ltd.), waarna zich opnieuw een recidiefstrictuur ontwikkelde op dezelfde plaats waarvoor eerder een open reconstructie werd uitgevoerd. Daarna ontwikkelde zich echter nogmaals een strictuur. De kans op succes van een tweede operatie werd klein geacht. Er werd voor gekozen om de stugge vernauwing op te rekken met een $8 \times 20 \mathrm{~mm}$-cutting balloon, gevolgd door stenting met een Overtoom-ballonkatheter als spacer balloon. De plaatsing van een enkele ballon zou de vlakbij gelegen anastomose aan de andere kant in gevaar kunnen brengen. Daarom werden er twee ballonnen geplaatst (fig. 3). De linker Overtoom-katheter viel na drie weken spontaan uit de Bricker-lis. De rechter werd vier weken na het inbrengen onder doorlichting verwijderd. In deze periode was geen nefrodrain aanwezig. Deze behandeling was uiteindelijk succesvol. $\mathrm{Na}$ anderhalf jaar ging het uitstekend met de patiënt en was er geen recidief meer opgetreden.

\section{Discussie}

Lekkage en stenoseproblematiek volgend op het creëren van een urinedeviatie lijkt in de literatuur een onderbelicht probleem te zijn. Doorgaans worden kleine series beschreven over minimaal invasieve oplossingen met wisselend succes $[1,2,4]$.

In deze serie beschrijven we de eerste ervaringen met de Overtoom-ballonkatheter. Dit is een ureteraal te plaatsen $\mathrm{JJ}$-katheter waaraan een ballon bevestigd is, die veilig in de ureter geplaatst kan worden en enkele weken (3-6 weken) in situ kan blijven. Deze ballon kan daarbij als langdurige dilatator gebruikt worden, bijvoorbeeld na het oprekken van een vernauwing met een peripheral cutting balloon voor bloedvaten (niet te verwarren met een Acucise ${ }^{\circledR}$-behandeling, waarmee de wand geheel gekliefd wordt). Met deze Overtoom-ballonkatheter kan ook een perforatie in een ureter (anastomose) worden overbrugd om lekkage op te heffen: als kidney blocker dus. Het lumen in deze JJ-katheter maakt passage door de katheter mogelijk, maar in de praktijk blijkt deze oplossing niet altijd afdoende. Bij twee van de drie hier beschreven patiënten bleek het toch noodzakelijk om een nefrostomiekatheter boven de ballon te plaatsen.

Bij het langer inlaten van de ballon kan de vrees bestaan dat door druknecrose een letsel ontstaat. Of door druk van
Figuur 3 Casus 3. a Positie van de Overtoom-ballonkatheters in beide ureteren. De distale uiteinden steken uit de Bricker-lis. Tevens is te zien dat de nefrostomiekatheter links is achtergelaten. b Positie van de Overtoom-ballonkatheters bij de overgang van de ureter naar de Bricker-lis, met de distale uiteinden in de stomazak.
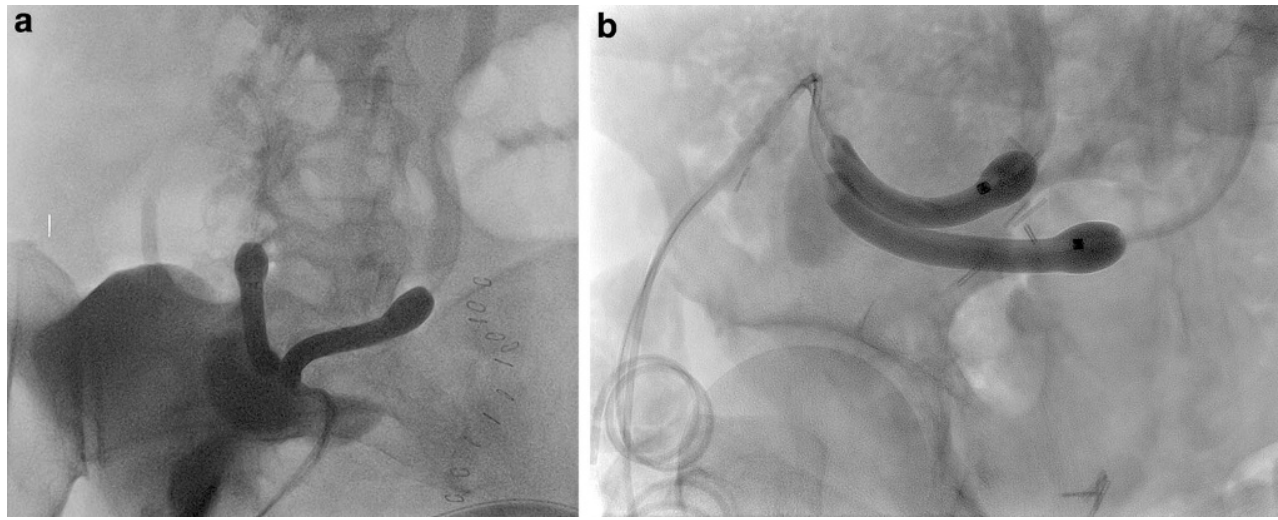
binnenuit letsel kan ontstaan, is niet bekend. Wel is er een beschrijving van druknecrose door druk van twee kanten (een JJ-stent en een vasculaire prothese) [6]. We hebben daar in deze beknopte serie geen aanwijzingen voor gezien.

Open Access This article is distributed under the terms of the Creative Commons Attribution 4.0 International License (http:// creativecommons.org/licenses/by/4.0/), which permits unrestricted use, distribution, and reproduction in any medium, provided you give appropriate credit to the original author(s) and the source, provide a link to the Creative Commons license, and indicate if changes were made.

\section{Literatuur}

1. Madersbacher S, Schmidt J, Eberle JM, et al. Long-term outcome of ileal conduit diversion. J Urol. 2003;169:985-90.

2. Zhang Z, Zhang C, Wu C, et al. Progressive ureteral dilations and retrograde placement of single-j stent guided by flexible cystoscope for management of ureteroenteral anastomotic stricture in patients after radical cystectomy and bricker urinary diversion. J Endourol. 2015;29:90-4

3. Thiruchelvam N, Harrison M, Page AC. The double wire technique: an improved method for treating challenging ureteroileal anastomotic strictures and occlusions. Br J Radiol. 2007;80(950):103-6.

4. Lin DW, Bush WH, Mayo ME. Endourological treatment of ureteroenteric strictures: efficacy of Acucise endoureterotomy. J Urol. 1999;162:696-8.

5. Overtoom TT, Vijverberg PL, Es HW van, Selm S van, Heesewijk HP van. Treatment of ureteropelvic junction obstruction using a detachable inflatable stent: initial experience. AJR Am J Roentgenol. 2009; 192:1103-6.

6. Sacks D, Miller J. Ureteral leak around an aortic bifurcation graft: complication of ureteral stenting. J Urol. 1988;140:1526-8.

dr. J.R. Oddens uroloog

drs. E.S.S. van den Aker uroloog

dr. P.L.M. Vijverberg uroloog

dr. H.H.E. van Melick uroloog

drs. T.T.C. Overtoom radioloog 